\title{
ANÁLISE INSTITUCIONAL DO MECANISMO DE PAGAMENTO POR SERVIÇOS AMBIENTAIS: o Projeto Conservador das Águas em Extrema - MG
}

\author{
Rafael Eduardo Chiodi \\ Instituto de Pesquisas Ecológicas (IPE) \\ Bruno Peregrina Puga \\ Universidade Estadual de Campinas (UNICAMP) \\ Oscar Sarcinelli \\ Instituto de Pesquisas Ecológicas (IPE)
}

\begin{abstract}
ANÁLISE INSTITUCIONAL DO MECANISMO DE PAGAMENTO POR SERVIÇOS AMBIENTAIS: o Projeto Conservador das Águas em Extrema - MG

Resumo: Mecanismos de incentivo econômico estão sendo acessados por políticas públicas para promover a conservação ambiental. O pagamento por serviços ambientais é um destes e, no Brasil, o Projeto Conservador das Águas em Extrema - MG é o seu caso de destaque. O trabalho analisa como a trajetória e as inter-relações institucionais determinaram a existência e o desenvolvimento deste projeto, considerando avanços e limitações do caso para a efetividade deste mecanismo. Conclui que a criação do projeto influenciou instituições formais e informais e promoveu inter-relações entre atores centrais e atores parceiros que foram fundamentais para os resultados alcançados. A estabilidade política, a experiência técnica, o interesse e dedicação pessoal do seu idealizador, juntamente com uma gestão central foram aspectos imprescindíveis à sua existência. Contudo, existem algumas limitações e preocupações no sentido do mecanismo conduzir a um reducionismo econômico para tratar de problemas complexos que tangem às relações entre sociedade e ambiente.
\end{abstract}

Palavras-chave: Políticas ambientais, instituições, Extrema, pagamento por serviços ambientais.

INSTITUTIONAL ANALYSIS OF MECHANISMS OF ENVIRONMENTAL SERVICES PAYMENT: the Water Conservation Project in Extrema - MG

Abstract: Economic incentive mechanisms are being accessed by public policies to promote environmental conservation. The environment services payment is one of these, and in Brazil the Water Conservation Project in Extrema - MG is its prominent case. The paper analyses how the trajectory and inter-institutional relations determinated the existence and development of this project, considering the advances and limitations of this case for the mechanism's effectiveness. It concludes that the project creation influenced formal and informal institutions and promoted inter-relationships among keyactors and stakeholders which were fundamental to the achieved results. The political stability, technical experience, the interest and personal dedication of its founder, along with a central management were essential aspects to the project's existence. However, there are limitations and concerns that the mechanism leads to economic reductionism to deal with complex problems that concerns to the relations between society and environment.

Key words: environmental policies, institutions, Extrema, payment for environmental services. 


\section{INTRODUÇÃO}

A realização da I Conferência das Nações Unidas para o Ambiente Humano em Estocolmo, em 1972, marcou a entrada da questão ambiental na agenda política mundial. No Brasil, seus reflexos foram pressões externas e internas que impulsionaram um movimento de expansão da ação governamental, refletindo na implementação de políticas públicas de governo mais explícitas com a criação de novas instituições para o tema (ACSELRAD, 2001). Neste contexto, as políticas públicas ganharam centralidade por serem os processos de tomada de decisão que afetam a coletividade e condicionam o conjunto da sociedade (ASSUMPÇÃO RODRIGUES, 2010). No campo ambiental, essas políticas são capazes de criar, reafirmar e alterar as instituições (PAAVOLA, 2007), que são as regras formais (constituições, leis e direitos de propriedade) e informais (costumes, tradições e códigos de conduta) que moldam o comportamento dos atores (NORTH, 1991).

As principais políticas públicas e instituições criadas no Brasil para tratar da questão ambiental tiveram como características a busca pela descentralização, com a delegação de responsabilidades aos estados e municípios (SCARDUA; BURSZTYN, 2003), e a priorização de instrumentos de comando e controle, que se apoiam na regulamentação direta, acompanhada de fiscalização e sanção para o não-cumprimento das normas e padrões estabelecidos (MAGRINI, 2001). Contudo, algumas novas políticas ambientais vêm priorizando instrumentos que têm como base o incentivo econômico. Os mecanismos de pagamento por serviços ambientais (PSA) surgem de forma descentralizada e com a crença de que o incentivo econômico seria mais efetivo que os instrumentos de comando e controle para mobilizar os atores para a proteção das águas e florestas (KOSOY et al, 2007).

O PSA nasce da problemática ambiental como um mecanismo de incentivo a gestão sustentável dos recursos naturais (WUNDER, 2007). Os serviços ambientais abrangem as intervenções que favorecem as condições e os processos pelos quais os ecossistemas mantêm suas funções e sustentam a vida (DAILY, 1997). Dessa forma, quem promove a manutenção ou a melhoria dos serviços ecossistêmicos está promovendo um serviço ambiental. O mecanismo de PSA pode ser definido como sendo uma transferência de recursos entre atores sociais, a qual objetiva criar incentivos para alinhar decisões individuais ou coletivas de uso da terra com o interesse social na gestão de recursos naturais (MURADIAN et al., 2010).

No Brasil, o mecanismo de PSA para a conservação da água (PSA-Água), foi recentemente assimilado às políticas públicas ambientais. A sua materialização está mais avançada no bioma Mata Atlântica com a implementação de projetos inseridos ao escopo de políticas públicas federais, estaduais e municipais (VEIGA; GAVALDÃO, 2011). As políticas que investem neste mecanismo promovem a cooperação entre atores, o que cria uma diversidade de arranjos institucionais e, o caráter voluntário de participação (WUNDER, 2007). Em nível nacional o Projeto Conservador das Águas no município de Extrema-MG é o caso de maior destaque, porque foi o primeiro projeto com base legal estabelecido no país e porque alcançou resultados práticos significativos (PAGIOLA; CARRASCOSA; TAFARELLO, 2012).

Partindo deste contexto, propõe-se aqui analisar o Projeto Conservador das Águas, considerando-o como a expressão de um mecanismo inovador acessado pela política ambiental para a gestão dos recursos hídricos. Para a tarefa, escolheu-se como instrumental teórico, o modelo neoinstitucionalista de análise de políticas públicas, pois dirige atenção às instituições em si e, também aos próprios atores políticos envolvidos no processo de implementação das políticas (FREY, 2000).

O artigo destaca e discute como a trajetória e as inter-relações institucionais e entre os atores sociais determinaram a existência e o desenvolvimento do Projeto Conservador das Águas, considerando avanços e limitações do caso para a efetividade deste novo mecanismo da política ambiental. $\mathrm{Na}$ segunda seção delimita-se o referencial teórico do objeto a ser analisado e do instrumental escolhido. $\mathrm{Na}$ terceira seção são apresentadas as características ambientais, socioeconômicas e políticas presentes no contexto estudado, além de resultados materiais alcançados pelo projeto. Na quarta seção, é descrita a trajetória temporal que forneceu as bases para a sua construção, mostrando as interfaces com outras esferas da política ambiental; apresentam-se as principais instituições formais e informais no contexto anterior ao projeto e analisam-se as inter-relações institucionais decorrentes da sua efetivação; e, categorizam-se os atores envolvidos, identificando suas inter-relações e seus papéis na proposição, gestão e resultados.

O estudo de caso foi o método utilizado, que possibilitou por meio de informações qualitativas, tentar desenvolver declarações teóricas mais gerais sobre as regularidades dos processos e estruturas sociais existentes no objeto em análise (BECKER, 1997). Para contextualizar as dimensões locais e os resultados do projeto, conduziu-se uma investigação indireta, composta pela pesquisa documental - arquivos públicos (leis, decretos e circulares informativas) e pesquisa bibliográfica - periódicos especializados, livros e relatórios. Para análise institucional e dos atores, além da investigação indireta conduziu-se uma pesquisa de campo.

$\mathrm{Na}$ pesquisa de campo, optou-se pela entrevista semiestruturada como a principal 
técnica de investigação. As entrevistas ocorreram no decorrer de 2012, quando o idealizador e coordenador do projeto foi entrevistado para compreender como ocorreu a concepção da política e o papel dos atores nela envolvidos. Além disto, foram entrevistados 61 proprietários rurais ${ }^{1}$ em oito municípios da região. As entrevistas extrapolaram os limites do município de Extrema, pois se pretendia entender de forma regional quais eram as instituições formais e informais determinantes para o acesso e uso dos recursos naturais. Os proprietários rurais foram escolhidos por possuírem recursos naturais disponíveis na propriedade, como nascentes, cursos d'água ou florestas, e os municípios por estarem inseridos na área de contribuição dos reservatórios do Sistema Produtor de Água Cantareira².

\section{A ANÁLISE INSTITUCIONAL PARA AVALIAR A EFETIVIDADE DA POLÍTICA DE PAGAMENTO POR SERVIÇOS AMBIENTAIS NO BRASIL}

O Estado brasileiro foi determinante no estabelecimento de uma legislação ambiental ampla e no estabelecimento de instrumentos de comando e controle para tratar dos problemas de regulação e uso dos recursos naturais (MAGRINI, 2001). Porém, o Código Florestal (BRASIL, 1965) pode ser um exemplo emblemático das dificuldades de efetividade deste tipo de instrumento. Este vigorou por 47 anos, sendo a principal instituição formal estabelecida para promover a conservação de recursos naturais em propriedades rurais. Em linhas gerais, havia duas disposições centrais: a) determinava que um percentual da área do imóvel rural, variável para cada bioma, fosse mantido com vegetação nativa a título de reserva legal (RL); e, b) determinava a obrigatoriedade de manter as Áreas de Preservação Permanente $(\mathrm{APP})^{3}$ existentes na propriedade. No entanto, no período em que vigorou, o passivo de $\mathrm{RL}$ (diferença entre o estabelecido na lei e a porção real protegida na prática) foi estimado em 159,3 milhões de hectares $(61,7 \%$ da área total prevista na lei). No bioma Mata Atlântica (RL de $20 \%$ da área do imóvel), o passivo em pequenas propriedades rurais aproximou-se de 4 milhões de hectares (INSTITUTO DE PESQUISA ECONOMICA APLICADA, 2011).

Com isso, torna-se importante refletir sobre o porquê do Código Florestal não ter alcançado seus objetivos. Primeiro, pode ser considerado que em países com instituições democráticas novas, como o Brasil, o comportamento dos atores não é totalmente moldado pelas instituições, este grau depende da consolidação do aparato institucional em questão. As peculiaridades socioeconômicas e políticas das sociedades em desenvolvimento permitem uma multiplicidade e inconstância dos arranjos institucionais, dos processos políticos e dos posicionamentos e atitudes ideológicas, que dificultam o cumprimento das regras impostas por esferas estatais. Segundo, nestes contextos, encontram-se instituições não formalizadas que exercem influência nos processos decisórios, como o clientelismo, o patrimonialismo e a corrupção, que interferem na efetividade destas instituições (FREY, 2000).

Estas explicações apoiam que algumas instituições formais não sejam aceitas e cumpridas pelos atores. Esta conclusão, ao mesmo tempo em que explica os motivos da possível não efetividade de instituições estatais para a conservação ambiental em países em desenvolvimento, expõe a limitação da própria análise estritamente institucional para entender esta falta de efetividade. Por isso, e também pelo enfraquecimento de instituições estatais em democracias modernas, cresceu a ênfase na concepção de governança (FREY, 2000). A governança consiste em um modo de governar mais cooperativa entre os diferentes atores sociais, onde o Estado e os governos deixam de exercer sua autoridade hierárquica sobre o processo de formulação de políticas (MAYNTZ, 2001). No campo ambiental, o conceito de governança, aqui considerado, está atrelado ao processo de estabelecimento, reafirmação ou mudança de instituições para resolver conflitos relacionados aos recursos naturais (PAAVOLA, 2007). Desse modo, os indivíduos, grupos ou organizações que possuem algum papel na arena política são os atores capazes de agir sobre estes processos (ASSUMPÇÃO RODRIGUES, 2010).

Devido a isto, aproxima-se aqui do modelo neoinstitucionalista de análise de políticas públicas, pois este além de enfatizar a importância crucial das instituições para a decisão, formulação e implementação de políticas públicas, também, considera as transformações institucionais como importantes para o entendimento do sucesso ou fracasso de determinadas políticas, destaca o papel e os objetivos dos atores políticos e os instrumentos da ação (SOUZA, 2006).

Um relevante conceito para a análise é o de "dependência da trajetória". Tal conceito mostra que as instituições se desenvolvem ao longo da história e que o processo através do qual as instituições de hoje são formadas não é somente relevante, como também constrange as escolhas futuras. Este conceito considera que as mesmas forças ativas não produzem em todos os lugares os mesmos resultados, pois essas forças são modificadas pelos contextos locais que dependem de heranças do passado (HALL; TAYLOR, 2003). Somado à trajetória, considera-se que as instituições são desenhadas e implementadas em distintos níveis de organização social, variando de regimes internacionais até regras de gestão comunitária. Isto permite a compreensão da chamada "inter-relação institucional" que propõe entender como instituições distintas (formais ou informais), mutuamente se afetam através de níveis 
de solução de governança e como estas interações influenciam os resultados práticos das políticas (CORBERA; BROW, 2008).

Desse modo, partindo da percepção das limitações dos instrumentos de comando e controle para conservação dos recursos naturaise, da crença que o incentivo econômico pode ser um mecanismo mais efetivo, emergem as políticas públicas de PSA (KOSOY et al, 2007). Acredita-se que estas políticas possam promover transformações em instituições vigentes e estabelecer novas regras e procedimentos para a conservação e, por surgir dentro da tendência da governança, que propõe políticas de caráter multisetorial e mais participativas, acredita-se que pode obter resultados institucionais mais efetivos, promovendo mudanças de comportamento mais consistentes nos atores envolvidos.

3 O CASO DE EXTREMA: o Projeto Conservador das Águas

O município de Extrema está localizado na cadeia de montanhas denominada Serra da Mantiqueira, por isso, possui relevo com declives acentuados. A precipitação média anual varia de 1.600 a $1.800 \mathrm{~mm}$. As condições geográficas da região, a forte radiação solar e a proximidade do oceano constituem pré-condição às precipitações acentuadas e significativa disponibilidade hídrica (COBRAPI, 2010).

Extrema é um dos quatro municípios mineiros que integram os Comitês das Bacias Hidrográficas dos Rios Piracicaba, Capivari e Jundiaí (Comitês PCJ). Praticamente toda a área do município (24.300,00 hectares) está inserida na Bacia Hidrográfica do Rio Jaguari. O rio Jaguari é o responsável pelo abastecimento do município e a sua bacia hidrográfica é a principal contribuidora do Sistema Produtor de Água Cantareira. Este sistema, considerado um dos maiores do mundo, faz a transposição de $33 \mathrm{~m}^{3} / \mathrm{s}$ de água da Bacia do Rio Piracicaba para a Bacia do alto Tiete e é responsável pelo abastecimento de aproximadamente nove milhões de pessoas na Região Metropolitana de São Paulo. A área total de contribuição dos seus seis reservatórios é de 228 mil hectares e abrange territórios de quatro municípios mineiros e oito paulistas (WHATELY; CUNHA, 2007).

Além da importância estratégica como "produtor de água" o município destaca-se em termos econômicos. Uma política de incentivos fiscais atraiu importantes empreendimentos. Destaca-se um setor industrial recente e crescente com a presença de empresas dos ramos mecânico, agroindustrial, eletroeletrônico, confecções, calçados, minerais nãometálicos, dentre outros. Em 2010, a população do município era de 28.564 habitantes e o PIB municipal chegou a $\mathrm{R} \$ 1.969 .542 .000,00$, o segundo maior entre os doze municípios da área de contribuição do
Sistema Cantareira (INSTITUTO BRASILEIRO DE GEOGRAFIA E ESTATÍSTICA, 2010).

Figura 1 - Delimitação da área de contribuição do Sistema Cantareira, municípios pesquisados com destaque para Extrema - MG

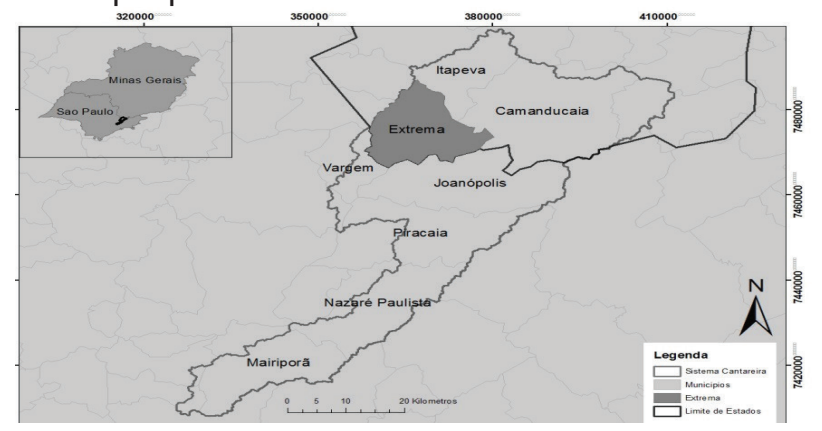

Fonte: INSTITUTO DE PESQUISAS ECOLÓGICAS, 2012.

O meio rural é marcado pela atividade agropecuária, sendo que $62 \%$ do seu solo são ocupados por pastagens (INSTITUTO DE PESQUISAS ECOLÓGICAS, 2012). Há predominância da pecuária bovina extensiva para produção de leite e carne. O município já foi uma importante bacia leiteira, apesar da atividade leiteira não possuir mais a dinâmica de outros tempos, ainda se mantém ativa. Recentemente, o pasto vem perdendo espaço para os monocultivos de eucalipto, promovendo novos modos de usufruir da propriedade. A pequena e média propriedade rural são predominantes e os laços de tradição no modo de produção são marcantes, porém, novos moradores provenientes de grandes cidades estão adquirindo propriedades como segunda residência.

$\mathrm{Na}$ dimensão política há uma peculiaridade a ser destacada: a continuidade política-administrativa. O grupo político atualmente à frente da prefeitura municipal já está há sete mandatos na administração pública. Esta constância vem possibilitando a continuidade de certas políticas municipais.

É neste cenário que surge a Lei Municipal 2.100 de 21 de dezembro de 2005, que cria o Projeto Conservador das Águas, tornando-se a primeira Lei municipal no país a regulamentar o PSA para a conservação da água. A Lei objetiva: aumentar a cobertura vegetal em sub-bacias hidrográficas; implantar corredores ecológicos; reduzir os níveis de poluição difusa rural; difundir o conceito de manejo integrado de vegetação, solo e água; e, garantir a sustentabilidade socioeconômica e ambiental das práticas implantadas. Assim, a Lei visa prestar apoio financeiro aos proprietários rurais que cumpram metas de adequação ambiental.

$\mathrm{Na}$ prática, o projeto teve início em 2007, envolvendo 21 beneficiários de uma microbacia hidrográfica, contando com um investimento inicial de $\mathrm{R} \$ 16.165,00$ para o pagamento direto aos proprietários rurais. Em 2011, este número chegou a 100 proprietários sendo pagos pelo projeto em três microbacias, com um investimento 
de $R \$ 1.109 .814,00$ destinados exclusivamente ao pagamento. Atualmente, o valor pago aos proprietários é de $\mathrm{R} \$ 198,00$ por hectare por ano. O valor recebido é relativo ao tamanho da propriedade, que em média é de 30 hectares. O pagamento é feito de forma direta e mensal (PEREIRA, 2012).

Os recursos financeiros são, em maior parte, garantidos pelo orçamento público municipal e, em parte, captados da Secretaria Estadual de Meio Ambiente de Minas Gerais, dos Comitês PCJ, da Agência Nacional das Águas, dentre outros. A operacionalização do projeto é conduzida pela prefeitura de Extrema com equipe e estrutura própria, contudo, parcerias com diferentes setores da sociedade são firmadas para a execução das ações. A adesão é voluntária e os critérios de elegibilidade são: a propriedade rural deve estar inserida em uma das sub-bacias trabalhadas pelo projeto, a área deve ser maior ou igual a dois hectares e, ter o uso da água regularizado por meio da outorga de uso da água (PEREIRA, 2012).

Para destacar a escala do projeto, considerando o ano de 2010/2011, dentre os cinco principais projetos ${ }^{4}$ de PSA-Água em andamento na Mata Atlântica, aproximadamente $50 \%$ dos contratos assinados estavam no âmbito do Conservador das Águas. Em 2011 eram 2.849,18 hectares (mais de $10 \%$ da área total do município) dentro de propriedades particulares destinados a algum tipo de intervenção conservacionista. Foram plantadas 220.686 mudas de espécies nativas, construídas 150.901 metros de cerca, estabelecidos 100 hectares de terraços em pastagens e construídas mais de 1.000 bacias de contenção de águas pluviais. Por estes e outros resultados o projeto ganhou visibilidade e notoriedade nacional e vem acumulando exibições na mídia e prêmios socioambientais. (MINAS GERAIS, 2012)

\section{INSTITUIÇÕES E ATORES NA CONSERVAÇÃO DOS RECURSOS HÍDRICOS}

A conservação dos recursos hídricos, tomada como um problema público, tem colocado a efetividade das instituições e o papel dos atores sociais como elementos centrais na análise das políticas públicas ambientais. Os processos de estabelecimento, reafirmação ou mudança institucional buscam ser capazes de resolver os conflitos que emergem da relação entre o uso e conservação dos recursos hídricos. Desse modo, os indivíduos, grupos ou organizações que possuem algum papel na arena política são os atores capazes de agir sobre estes processos. Assim, a análise de novos instrumentos da política ambiental, como o pagamento por serviços ambientais, que criam novas instituições e que agregam diferentes atores sociais em sua efetivação, contribui para o entendimento dos desafios para a conservação dos recursos hídricos.

\subsection{A trajetória percorrida e interfaces com a política ambiental}

Para o idealizador do Conservador das Águas "o projeto foi uma evolução". O interesse político de representantes de municípios da região sul de Minas Gerais, em 1996, mobilizou esforços para a construção e execução do projeto "Recuperar e Preservar as Águas dos Mananciais de Consumo e Desenvolvimento do Médio Sapucaí". Esta proposta comum tinha três frentes de ação, a saber: restauração florestal, conservação de solos e saneamento básico no meio rural. Estas ações no futuro seriam as bases para o Projeto Conservador das Águas.

A mobilização surgiu em resposta a um estímulo externo, vinculado à política ambiental nacional. Os recursos disponibilizados saíam do Ministério do Meio Ambiente, pela linha Projetos de Execução Descentralizados (PED), que distribuía recursos do Programa Nacional de Meio Ambiente. Este era a materialização da ampliação da descentralização da gestão ambiental no País, pois apoiava ações propostas por municípios (SCARDUA; BURSZTYN, 2003). Este programa fomentou parcerias entre atores regionais para recuperar áreas de preservação permanente em propriedades rurais e, evidenciou o direcionamento da política ambiental a uma postura mais de incentivo do que de imposição.

A linha do PED fomentou a cooperação entre órgãos de diferentes níveis de governo, seis prefeituras municipais (gestoras do projeto), a Empresa de Assistência Técnica e Extensão Rural de Minas Gerais (EMATER) (executora) e o Instituto Brasileiro do Meio Ambiente e Recursos Naturais Renováveis (IBAMA) (apoio). A implementação da agenda ambiental nacional viabilizou uma interface organizacional no nível local para a execução de ações ambientais. Neste período, Extrema não tinha escritório da EMATER, mas destinou um funcionário da prefeitura para acompanhar o projeto; este acabou assumindo a coordenação regional dos trabalhos e tornou-se o principal idealizador e realizador do Conservador das Águas.

Contudo, em 1998, as ações deste projeto comum não alcançaram os resultados esperados devido à falta de adesão dos proprietários. Em vista disto, os gestores do projeto decidiram usar as regras definidas no Código Florestal para exigir adesões e garantir os resultados esperados. Com a atuação do IBAMA e do poder judiciário para "fazer-se cumprir a lei" as metas de reflorestamento e conservação de solos foram alcançadas. No entanto, ficou claro que o mecanismo de incentivo também não mostrou resultados satisfatórios e que a instituição imposta no nível nacional, não incorporada pelos atores, funcionou como um "poder de pressão para incentivar" alterações no modo de uso do solo nas propriedades rurais. 
Em 2001, já havia uma conjuntura política estável e conhecimento técnico acumulado para criar um projeto semelhante e exclusivo em Extrema. A limitação estava na disponibilidade de informações detalhadas do seu cenário socioambiental, além do desafio de pensar "modos mais amigáveis" de dialogar com os proprietários rurais. A execução de outro projeto denominado "Água é Vida - Manejo e Monitoramento em Sub-bacias Hidrográficas", financiado pelo Ministério do Meio Ambiente, permitiu a contratação de assessoria técnica, a aquisição de imagens de satélite, o cadastramento e georreferenciamento de propriedades e a subdivisão do município em sub-bacias hidrográficas. Ainda, viabilizou as negociações com os proprietários vinculados à Associação do Bairro das Posses (primeira microbacia trabalhada), anteriormente à criação do projeto. Neste momento ocorre outra interface com a política nacional, agora relacionada à dimensão operacional.

A Agência Nacional das Águas (ANA), responsável pela gestão dos recursos hídricos brasileiros, se aproximaria em $2002 \mathrm{com}$ o intuito de difundir o "Projeto Produtor de Água" que apoiava, financeiramente, iniciativas de proprietários rurais que adotassem medidas de conservação do solo. Assim, a partir da convergência entre a experiência e as informações técnicas acumuladas pelos projetos anteriores e a adesão e adaptação deste novo mecanismo de incentivo foi proposto o desenho técnico operacional do Projeto Conservador das Águas.

\subsection{Instituições formais e informais e suas inter- relações}

$\mathrm{Na}$ área do estudo, o Código Florestal e a Lei 11.428 , de 22 de dezembro de 2006 que definem os estágios sucessionais da vegetação nativa e seu regime de proteção no bioma Mata Attântica, podem ser considerados como as principais regras formais impostas pela política ambiental para a proteção dos recursos naturais em propriedades privadas. Estas leis acopladas de seus meios de efetivação, fiscalização e controle, foram insuficientes para manter o grau de cobertura florestal por eles prédeterminados. Em 2007, na área de contribuição do Sistema Cantareira, cerca de $46 \%$ das APPs ao longo dos cursos d'água não estavam ocupadas por florestas, mas por pastos, cultivos de eucalipto, agricultura ou algum uso urbano (INSTITUTO DE PESQUISAS ECOLÓGICAS, 2012).

As determinações do Código Florestal foram as mais conhecidas pelos proprietários rurais entrevistados, mas são pouco entendidas. Estes sabiam das proibições para utilizar áreas próximas às nascentes e cursos d'água, mas não necessariamente as cumpriram. Isto permite concluir a fragilidade desta instituição formal imposta em nível nacional. Algumas podem ser as explicações: primeiro, os meios capazes de transmitir esta norma não foram priorizados ou não são eficazes; segundo, esta instituição não considera outras instituições formais e informais em nível local (direito de propriedade e o modo tradicional de uso do solo), assim, o efeito de uma anula ou altera o resultado da outra; terceiro, a limitada capacidade de policiamento para com aqueles que descumprirem as normas, além da corrupção de agentes e órgãos ambientais; e, quarto, a interferência de variáveis como, conjuntura econômica local (valorização imobiliária ou incentivos para a expansão de uma determinada atividade produtiva), questões familiares (partilha de terra) e necessidades produtivas (expansão ou manutenção da produção).

No entanto, 0 modo de agir perante a propriedade e aos recursos naturais disponíveis dentro dela está mais determinantemente delineada pelo direito de propriedade, se apresentando como uma instituição forte. Dentre os entrevistados cerca de $90 \%(\mathrm{~N}=61)$ declararam possuir documentação referente ao imóvel rural, dentre estes, $62 \%$ $(\mathrm{N}=55)$ declararam possuir a documentação completa (escritura e matrícula do imóvel) e $36 \%$ $(\mathrm{N}=55)$ declararam possuir somente a escritura. A propriedade privada da terra determina, como instituição formal, a liberdade de acesso ao recurso e a possibilidade de estabelecer ou não medidas de conservação. Destaca-se, que a significativa disponibilidade de água da região, não promoveu sérios conflitos pelo seu uso e não propiciou arranjos coletivos para o seu acesso, contudo, fortaleceu acessos e decisões individualizadas. Contudo, notase que a tomada de decisão referente ao modo de uso da propriedade é um processo dinâmico que sofre influências de múltiplos fatores, alguns deles já descritos acima.

O direito "consagrado" de usufruto sobre a propriedade privada conjuntamente a instituições informais como o costume, a tradição, o modo de uso passado de pai para filho foram mais determinantes para moldar o comportamento dos proprietários rurais. A busca pela prosperidade socioeconômica familiar do passado regrou e definiu o comportamento diante dos recursos da propriedade: a ocupação dos terrenos mais produtivos (ao longo dos cursos d'água), o uso de técnicas que exigem menor trabalho para renovar as pastagens (queimadas) e a limpeza total do terreno (maior lotação de animais). Esses comportamentos degradam as condições ambientais, mas otimizam os recursos produtivos disponíveis. Ainda, a abundância de recursos naturais impede a preocupação com a preservação ambiental, porque, se utilizada, aumenta a produtividade familiar.

Contudo, vale ressaltar que os impactos das regras do Código Florestal afetam o modo de uso das propriedades de forma diferenciada, dependendo da finalidade que se dá a esta. Devido à predominância de pequenas e médias propriedades rurais de caráter familiar, ficou nítida uma relação 
inversamente proporcional entre aceitação de regras ambientais e prosperidade socioeconômica familiar. Muitos produtores rurais encaram o cumprimento destas normas como prejudiciais, pois levam à perda de áreas produtivas e à perda de produção, por consequência, à diminuição da renda familiar e à frustração da família enquanto produtores rurais. Já a percepção destas normas é completamente diferente para aqueles que não dependem da propriedade rural para a geração de emprego e renda familiar; estes podem dispor, mais facilmente, de áreas para a conservação.

Wunder (2007) sugere que a efetividade da implementação do PSA pode ser mais difícil onde as instituições são frágeis. No caso estudado, o desenho de PSA tenta fortalecer as instituições frágeis, a legislação ambiental, por meio da intervenção em instituições fortes, a propriedade privada e a tradição no modo de uso do solo. Neste sentido, dois aspectos se destacam: o primeiro é que o projeto está permitindo o acesso ao interior da propriedade privada e a promoção de mudanças concretas no seu modo de uso, conseguindo o que outras políticas ambientais não efetivaram. Assim, uma nova regra formal está alterando instituições informais altamente enraizadas no modo de vida local. O segundo é que o projeto está favorecendo a assimilação das instituições formais junto aos proprietários, estas que, por sua vez, não foram completamente efetivadas. No entanto, a penetração de novas possibilidades para a propriedade rural pode promover em longo prazo mudanças permanentes no comportamento dos envolvidos.

O Projeto Conservador das Águas por meio da prestação de apoio financeiro aos proprietários rurais vem conseguindo promover ações de melhoria da qualidade e quantidade das águas no município. Contudo, segundo avaliação conduzida por Gavaldão (2008), aproximadamente 50\% dos ingressos ao projeto ocorreram de forma não voluntária. $O$ incentivo financeiro não se mostra totalmente efetivo para a adesão ao projeto, e a "pressão para o incentivo" ainda está presente. Neste caso, percebe-se que não há um mecanismo genuíno de incentivo, e sim a conjunção do incentivo econômico e de certa imposição. Kosoy e outros (2007) estudando programas de PSA na América Central, mostraram que as relações sociais, o poder de negociação, os direitos de propriedade e outros aspectos institucionais são provavelmente mais importantes para a adesão em projetos de PSA do que somente a valoração e a negociação econômica. A análise do caso de Extrema corrobora com isto, e clarifica as limitações deste novo mecanismo, por si só, para promover a mudança de comportamento voluntária dos proprietários rurais.

O obstáculo do interesse voluntário é destacado pelo coordenador do projeto quando afirma que apoiar financeiramente proprietários para protegerem os recursos hídricos não seria suficiente para o sucesso da proposta. Ele diz que é preciso conduzir todas as etapas do processo: mapear a propriedade, fazer as cercas, conseguir as mudas, realizar os plantios e as práticas de conservação de solos, e realizar a manutenção das áreas. Não sendo assim, os proprietários não seriam capazes de realizar estas ações, pois não teriam o conhecimento apropriado e o devido interesse. Deste modo, este desenho transparece um alto grau de dependência e um caráter assistencialista. A relação de dependência criada pode promover o que Wunder (2007) chama de "baixa permanência", que seria ao término do projeto o retorno das áreas trabalhadas a situação anterior a sua execução. Esta possibilidade aumenta devido aos crescentes custos de transação, pois esta política está amplamente estimulada e limitada pela capacidade de uma troca financeira, //onde o custo/benefício para ambas as partes está em constante ponderação.

Aqui, deve-se ainda, destacar a preocupação deste mecanismo transformar os recursos naturais comuns em "commodities", ou seja, mercadorias homogêneas com preço de mercado, com vistas às instituições de mercado regular o seu uso e acesso. Este caminho induz ao extremo reducionismo, desconsiderando a complexidade dos sistemas sociais e ecológicos, pois: a) torna invisível a complexidade das interações ecológicas, porque como mercadoria, é necessário delimitarexatamenteoquese desejanegociar (definição de como e quanto uma ação de conservação pode melhorar o serviço ambiental); b) induz a anulação de outros valores sociais que emergem das relações entre sociedade-natureza, priorizando somente o valor econômico; e, c) desconsidera assimetrias institucionais relacionadas aos direitos de propriedade, excluindo os que não possuem propriedade privada. (KOSOY; CORBERA, 2010)

\subsection{Os atores, seus papéis e suas inter-relações}

No cenário do Conservador das Águas os atores podem ser divididos dentro de duas categorias: a) atores centrais, subdivididos em público e privado; e, b) atores parceiros. Os atores centrais conformam o núcleo da política; sem estes, esta não existiria. Os atores públicos são os agentes do poder público municipal, que podem ser subdivididos em atores políticos, o poder executivo e o legislativo, e atores técnicos, os funcionários gestores do projeto. Esta subdivisão é relevante, pois os atores políticos têm o poder de decisão sobre as regulamentações, já os atores técnicos possuem a capacidade de executar as determinações, e foi a conjunção destas capacidades que permitiu a existência e o desenvolvimento do projeto. Os atores públicos são responsáveis pela gestão administrativa, técnica e financeira do projeto, além de toda a assistência técnica. Os atores privados são os proprietários rurais, definidos como provedores-recebedores do serviço ambiental. 
A estabilidade política no nível municipal possibilitou interações entre os atores centrais, as quais podem ser consideradas como positivas para explicar a existência do projeto. A primeira interação está no espaço dos próprios atores públicos (técnico e político), que se aproximaram para priorizar ações ambientais no município. Esta aproximação alinhada por afinidades políticas-partidárias permitiu que o projeto fosse criado e recursos do orçamento público e apoios estruturais garantidos. A segunda está na relação entre ator central público (técnico) e privado. A relação estabelecida entre o corpo técnico da prefeitura e as associações de bairro, representantes dos proprietários, abriu um canal de participação anterior ao próprio projeto, que foi fundamental para sua viabilidade prática.

Os atores parceiros foram os que contribuíram com o projeto em algum momento de sua trajetória; eles compõem uma constelação ao redor dos atores centrais. Individualmente, estes não foram imprescindíveis ao projeto, porém, injetaram grande aporte de recursos e permitiram sua rápida expansão. O coordenador do projeto diz: "Não buscamos parceiros para viabilizar a ideia, e sim para viabilizar o projeto". A proposta já estava pronta e os parceiros foram procurados para sua realização e para suprir e fortalecer componentes relevantes do seu escopo. A prefeitura controla diretamente os principais elos do processo, a negociação com os proprietários, o diálogo com os atores parceiros e a gestão orçamentária. Vatn (2010) aponta ser este o desenho mais usual em esquemas de PSA, pela dificuldade em delimitar os serviços ambientais como mercadoria e especificar quem são os seus provedores e os seus usuários, assim, o intermediário do sistema tem o poder de definir qual serviço ambiental será recompensado, estabelecer quem será o comprador e o recebedor e qual será o preço pago.

O desenho do projeto imputa uma flexibilidade relativa e restrita à participação. Na relação entre atores centrais públicos e atores parceiros não há canais formais de participação e concertação, as decisões são tomadas centralmente. Na relação entre equipe técnica e proprietários há flexibilidade no que diz respeito às práticas e manejos propostos, os proprietários podem decidir, através de uma negociação, quais medidas de adequação ambiental serão adotadas. Por isso, este arranjo ainda está distante da concepção que a flexibilidade nos processos de desenho e adaptação institucional é central para assegurar a efetividade de longo prazo de novas instituições para a conservação, devido às possibilidades de correção dos erros de percurso (CORBERA; GONZALÉS SOBERANIS; BROW, 2009).

Os atores parceiros provieram de diferentes setores da sociedade - estado, iniciativa privada e sociedade civil, como pode ser visto na Tabela 1 . Os recursos aportados também foram distintos, a saber: a) técnico e de treinamento; b) financeiro: financiamento de ações, pagamentos e subsídios; c) conhecimento: informações e educação ambiental; d) material: equipamentos, mudas e mourões.

A mobilização destes atores foi preponderante para agregar conhecimento e capacidade técnica para conduzir o projeto, concluindo que isto foi central para os resultados alcançados. Contudo, cada ator parceiro possui objetivos específicos que os motivaram a entrar no projeto, de modo geral, eles buscam cumprir metas próprias. Há casos de parceiros que oferecem apoios contínuos como a Secretaria de Meio Ambiente de Minas Gerais e os Comitês PCJ, outros mais pontuais que visam melhorar sua imagem ambiental perante a sociedade.

Tabela 1 - Atores parceiros, seus papéis e o nível de governança no Projeto Conservador das Águas

\begin{tabular}{l|l|l}
\multicolumn{1}{c|}{ Atores } & \multicolumn{1}{c}{ Ação- papel } & Nível de governança \\
\hline $\begin{array}{l}\text { Secretaria de Meio Ambiente e De- } \\
\text { Genvolvimento Sustentável de Minas } \\
\text { - MG }\end{array}$ & $\begin{array}{l}\text { Fornecimento de materiais de consumo } \\
\text { Fornecimento de equipamentos (veículos) } \\
\text { Gestão de recursos financeiros para PSA } \\
\text { Apoio ao processo de comando e controle } \\
\text { Apoio técnico }\end{array}$ & \\
\hline Agência Nacional de Águas & $\begin{array}{l}\text { Apoio técnico } \\
\text { Monitoramento da água } \\
\text { Ações de conservação de solo }\end{array}$ & Nacional \\
\hline The Nature Conservancy & $\begin{array}{l}\text { Financiamento das ações de plantio } \\
\text { Manutenção e cercamento das áreas }\end{array}$ & Internacional \\
\hline SOS Mata Atlântica & $\begin{array}{l}\text { Monitoramento socioambiental } \\
\text { Apornecimento de equipamentos }\end{array}$ & \\
\hline Comitês PCJ & Fornecimento de mudas de árvores & \\
\hline Bauducco Alimentos & Financiamiconto de projetos executivo & Regional \\
\hline Laticínio Serra Dourada & Pegada Hídrica e Pegada Ecológica & Regional \\
\hline Indústria Dalka do Brasil & Subsídio financeiro. & Local \\
\hline Auto Pista Fernão Dias & Doação de Biodigestores & Local \\
\hline Empresa Melhoramentos & Restauração florestal & Local \\
\hline Universidades & Mourões e Mudas de árvores nativas & Regional \\
\hline
\end{tabular}

Fonte: Pereira (2012). 
Diante disto, fica nítido que o projeto emergiu de uma perspectiva de governança que estava baseada na inter-relação institucional em multiníveis, operando no local, regional, nacional e internacional (CORBERA; BROW, 2008), porém foi no local que forças agregadoras de oportunidades catalisaram os estímulos externos.

\section{CONCLUSÃO}

A implementação de uma agenda ambiental a nível nacional fomentou a mobilização e a organização de atores a nível regional e municipal e supriu importantes demandas operacionais que foram determinantes para a existência do Conservador das Águas. A criação deste projeto promoveu a mobilização de atores parceiros para atuar a nível municipal, que foi relevante para os seus resultados. Contudo, a estabilidade política, a experiência técnica acumulada, o interesse e dedicação pessoal do seu idealizador, juntamente com uma gestão central foram aspectos imprescindíveis à sua existência e aos seus resultados.

As principais instituições formais identificadas anteriormente à criação do projeto foram o direito de propriedade (instituição forte) e as leis ambientais (instituições fracas). As instituições informais foram o costume e tradição no modo de uso do solo. A conjunção entre o direito de propriedade e os modos tradicionais de produção foi identificada como determinante para moldar o comportamento dos atores diante dos recursos naturais, porém, outros fatores foram centrais para entender esta relação no contexto estudado.

$\mathrm{O}$ projeto permitiu o acesso à propriedade privada e promoveu mudanças diante do uso da propriedade entre os beneficiários, porém, não alcançou a total adesão voluntária destes. Por isso, acredita-se que o incentivo econômico aparenta ser um mecanismo limitado para atrair todos os proprietários rurais, e, portanto, outras variáveis devem ser percebidas. Além disso, pode ser considerado o seu reducionismo econômico para intervir em sistemas sociais e ecológicos complexos. Contudo, o incentivo econômico alcançou resultados mais consistentes que as instituições formais existentes (legislação ambiental). No entanto, o grau de dependência estabelecido pode fazer que os resultados retrocedam no futuro, devido a uma possível "baixa permanência", ou, podem promover mudanças de comportamento permanentes em favor da conservação.

Enfim, os atores centrais, principalmente os públicos, foram preponderantes para proposição e gestão do projeto e determinantes para a existência do mesmo. Os atores parceiros tiveram importância no campo técnico e financeiro, o que garantiu a qualidade dos resultados significativos alcançados. Além disso, o alinhamento de fatores como o ambiente físico dotado de significativa disponibilidade hídrica, a localização estratégica em termos geoeconômicos e a estabilidade política, fez de Extrema um cenário possível para esta experiência.

\section{REFERÊNCIAS}

ACSELRAD, H. Políticas Ambientais e construção democrática. In: VIANA, G.; SILVA, M.; DINIZ, N. O desafio da sustentabilidade: um debate socioambiental no Brasil. São Paulo: Editora Perseu Abramo, 2001. cap 4, p. 75-96.

ASSUMPÇÃO RODRIGUES, M. M. Políticas públicas. São Paulo: Publifolha, 2010.

BECKER, H.S. Métodos de pesquisa em ciências sociais. 3. ed. São Paulo: HUCITEC, 1997. 178 p.

BRASIL. Congresso Nacional. Lei n. 4.771 de 15 de setembro de 1965. Institui o Novo Código Florestal. Diário Oficial [da] Republica Federativa do Brasil, Poder Executivo, Brasília, DF, 15 set. 1965. Disponível em: <http://www.planalto.gov.br/ccivil_03/ leis/L4771.htm>. Acesso em: 20 nov. 2012.

COBRAPI. Plano das Bacias Hidrográficas dos Rios Piracicaba, Capivari e Jundiaí 2010-2020. Piracicaba: Agência das Águas PCJ, 2010.

CORBERA, E.; GONZALÉS SOBERANIS, C.; BROW, K. Institutional dimensions of Payments for Ecosystem Services: an analysis of Mexico's carbon forestry programme. Ecological Economics, Philadelphia, PA, v. 68, p. 743-761, 2009.

BROW, K. Building institutions to trade ecosystem services: marketing forest carbon in Mexico. World Development, Philadelphia, PA, v. 36, n. 10, p. 1956-1979, 2008.

DAILY, G. C. Introduction: what are ecosystem services? In: DAILY, G. C. Nature's services: societal dependence on natural ecosystems. Washington: Island Press, 1997. cap. 1, p. 1-10.

FREY, K. Políticas públicas: um debate conceitual e reflexões referentes à prática da análise de políticas públicas no Brasil. Revista Planejamento e Políticas Públicas, Brasília, n. 20, p. 211-259, jun. 2000.

GAVALDÃO, M. Avaliação da percepção ambiental e dos impactos sócio-econômicos do projeto "Conservador das Águas" Extrema, Minas Gerais, Brasil. [S.I.], nov. 2008. Relatório III de Resultados e Discussão.

HALL, P. A.; TAYLOR, R. C. R. As três versões do neo-institucionalismo. Lua Nova, São Paulo, n. 58, p. 193-224, 2003. 
INSTITUTO BRASILEIRO DE GEOGRAFIA E ESTATÍSTICA. Cidades. Brasília, DF, 2010. Disponível em: <www.ibge.gov.br/cidadesat/ topwindow.htm.> Acesso em: 04 set. 2012.

INSTITUTO DE PESQUISA ECONOMICA APLICADA. Código florestal: implicações do PL 1876/99 nas áreas de Reserva Legal, n. 96. Brasília, DF, 2011.

INSTITUTO DE PESQUISAS ECOLÓGICAS. Projeto Semeando Água: pagamento por serviços ambientais no corredor Cantareira-Mantiqueira. Relatório Final, Nazaré Paulista, 2012.

KOSOY, N.; CORBERA, E. Payments for ecosystem services as commodity fetishism. Ecological Economics, Philadelphia, PA, v. 69, p. 1228-1236, 2010.

et al. Payments for Environmental Services in Watersheds: insights from a comparative study of three cases in Central America. Ecological Economics, Philadelphia, PA, v. 61, p. 446-455, 2007.

MAGRINI, A. Política e Gestão Ambiental: conceitos e instrumentos. Revista Brasileira de Energia, Rio de Janeiro, v. 8, n.2, p. 135-147, 2001.

MAYNTZ, R. El Estado y la sociedade civil em la gobernanza moderna. Revista del CLAD Reforma y Democracia, Caracas, n. 21, p. 1-8, oct. 2001.

MINAS GERAIS. Prefeitura Municipal de Extrema. Conservador das águas: 6 anos. Extrema, 2012.

MURADIAN, R. et al. Reconciling theory and practice: An alternative conceptual framework for understating payments for environmental services. Ecological Economics, Philadelphia, PA, v. 69, p. 1202-1208, 2010.

NORTH, D. Institutions. The Journal of Economic Perspectives, Pittsburgh, PA, v. 1, n. 5, p. 97-112, 1991.

PAAVOLA, J. Institutions and environmental governance: a reconceptualization. Ecological Economics, Philadelphia, PA, v. 63, p. 93-103, 2007.

PAGIOLA, S.; CARRASCOSA, H. V.; TAFARELLO, $D$. Experiências de pagamento por serviços ambientais no Brasil. São Paulo: SMA - SP/CBRN, 2012. $274 \mathrm{p}$.

PEREIRA, P. H. Projeto Conservador das Águas - Extrema. In: PAGIOLA, S.; CARRASCOSA, H. V.; TAFARELLO, D. (Org.). Experiências de pagamento por serviços ambientais no Brasil. São Paulo: SMA - SP/CBRN, 2012. cap. 2, p. 29-40.
SCARDUA, F.P.;BURSZTYN, M.A.A. Descentralização da política ambiental no Brasil. Sociedade e Estado, Brasília, v. 18, n. 1/2, p. 219-314, jan./dez. 2003.

SOUZA, C. Políticas públicas: uma revisão da literatura. Revista Sociologias, Porto Alegre, n. 16, p. 20-45, jul./ dez. 2006.

VATN, A. An institutional analysis of payments for environmental services. Ecological Economics, Philadelphia, PA, v. 69, p. 1245-1252, 2010.

VEIGA, F.; GAVALDÃO, M. Iniciativas de PSA de conservação dos recursos hídricos na Mata Atlântica. In: GUEDES, F. B.; SEEHUSEN, S. E. Pagamento por serviços ambientais na Mata Atlântica: lições aprendidas e desafios. Brasília: MMA, 2011.

WHATELY, M.; CUNHA, P. Cantareira 2006: um olhar sobre o maior manancial de água da Região Metropolitana de São Paulo. [S.I.], 2007. Disponível em: <http://www.mananciais.org.br/upload/cantareira2006. pdf.> Acesso em: 02 jun. 2010.

WUNDER, S. Theefficiency of PaymentsforEnvironmental Services in Tropical Conservation. Conservation Biology, Malden, MA, v. 21, n. 1, p. 48-58, 2007.

Notas

Os proprietários são na maioria produtores rurais que desenvolvem atividades como pecuária de leite e/ou de corte, produção de eucalipto, produção de batata, hortaliças e morango e, alguns possuem a propriedade para fins de lazer. O trabalho familiar é preponderante e as técnicas de produção são de baixa tecnologia. O tamanho médio das propriedades é cerca de 40 hectares.

2 Os municípios mineiros de Extrema, Camanducaia e Itapeva, e os municípios paulistas de Vargem, Joanópolis, Piracaia, Nazaré Paulista, Mairiporã.

3 Ao longo de cursos d'água (mínimo 30 metros), ao redor de lagos, lagoas e reservatórios, entorno de nascentes (50 metros de raio), topos de morros, áreas com declive maior que $45 \%$, entre outros.

4 Conservador das Água/MG; Projeto Piloto Produtor de Água da Bacia dos Rios Piracicaba, Capivari e Jundiaí/ SP; Projeto Produtor de Água na Bacia do Rio Benevente/ ES; Projeto Produtor de Água na Bacia do Rio Guandu/ ES; Projeto Produtores de Águas e Florestas/RJ.

Rafael Eduardo Chiodi

Engenheiro Florestal

Doutorando em Ecologia Aplicada Interunidades (ESAL) da Universidade de São Paulo (USP)

Pesquisador associado ao Instituto de Pesquisas Ecológicas (IPÊ)

Doutorando pela CENA-ESALQ/USP

E-mail: rafaelchiodi@yahoo.com.br 


\section{Bruno Peregrina Puga}

Economista

Mestrando em Desenvolvimento Econômico pela

Universidade Estadual de Campinas (UNICAMP)

E-mail: bppuga@gmail.com

\section{Oscar Sarcinelli}

Administrador

Doutorando em Desenvolvimento Econômico pela

Universidade Estadual de Campinas.

Pesquisador associado ao Instituto de Pesquisas

Ecológicas (IPE)

E-mail: oscarsarc@uol.com.br

Instituto de Pesquisas Ecológicas (IPE)

Rod. Dom Pedro I, km 47, Nazaré Paulista, SP

CEP: $12960-000$

\section{Universidade Estadual de Campinas (UNICAMP)}

Rua Pedro Zaccaria, 1300, Campus II, Jardim Santa Luzia

- Limeira - SP

CEP: $13084-350$ 